\title{
Apoio multicritério à decisão como subsídio à gestão ambiental: o caso da Aggreko Brasil
}

\author{
Application of a multicriteria decision method to support \\ environmental management: Aggreko - Brazil - case study
}

\author{
Damaris Paoli ${ }^{1}$ \\ Luzia Alice Ferreira de Moraes $^{2}$
}

\begin{abstract}
Resumo: Os impactos negativos relacionados à degradação ambiental levaram à formulação do paradigma do desenvolvimento sustentável. Os ambientes corporativos, pressionados pela sociedade, buscam, por meio da implementação de Sistemas de Gestão Ambiental (SGA), este novo modelo de desenvolvimento. O objetivo principal deste trabalho é apresentar um caso de decisão metodológica, que prioriza opções de alternativas. Foi utilizado o método Tomada de Decisão Interativa Multicritério (TODIM) como uma das ferramentas de decisão Multicritério. O estudo de caso focaliza uma filial de empresa multinacional localizada no Estado do Rio de Janeiro, que oferece soluções de energia temporária e sistemas de controle de temperatura. Foram selecionados oito funcionários de diferentes setores da empresa para a ponderação das alternativas, de acordo com os diferentes critérios qualitativos. Foi demonstrado que existem conflitos de opinião em relação à priorização das alternativas. Isso ocorreu devido à interdependência das alternativas e porque os diferentes atores visualizam o problema com perspectivas diferentes e têm interesses diversos. Os resultados mostraram que a principal alternativa, segundo a maioria dos atores, é a implementação de um programa de educação ambiental para evitar desperdícios e informar/conscientizar os empregados sobre as questões ambientais. Em segundo lugar, foi escolhido um plano para contenção de derrames.
\end{abstract}

Palavras-chave: Gestão ambiental. Empresa multinacional. Análise multicritério. TODIM.

\begin{abstract}
The negative impacts related to environmental degradation have led to the formulation of the sustainable development paradigm. Business environments, pressured by society seek this new development model through the implementation of environmental management systems. The main objective of this paper is to present a decisionmaking methodological framework, which prioritizes alternative options. The TODIM (Interactive Multicriteria Decision Making) method was used as one of the Multicriteria Decision-Making tools. The case study is a branch multinational corporation, located in Rio de Janeiro, which provides temporary power and temperature control solutions. Eight employees from different sectors of the company were selected to evaluate alternatives according to different qualitative criteria. It was shown that there is a conflict of opinion on ranking alternatives due to the interdependence of the alternatives and also because different actors see the problem from different perspectives and have different interests. The results showed that the main alternative, according to the majority of actors, is the implementation of an environmental education program to avoid wastes and to educate and inform employees about environmental issues. The second alternative chosen was the development of a spill containment plan.
\end{abstract}

Keywords: Environmental management. Multinational company. Multicriteria analysis. TODIM.

\section{Introdução}

No Brasil, a primeira definição legal de meio ambiente ocorreu com a edição da Lei n. 6.938, de 1981, que instituiu a Política Nacional de Meio Ambiente (PNMA), o qual foi considerado como um "[...] patrimônio público a ser necessariamente assegurado e protegido, tendo em vista o uso coletivo." (BRASIL, 1981, art. 2º I) e conceituado como “[...] o conjunto de condições, leis, influências e interações de ordem física, química e biológica, que permite, abriga e rege a vida em todas as suas formas." (BRASIL, 1981, art. $2^{\circ}$, I). No Art. $2^{\circ}$ da Lei 6.938, são tratados os objetivos da PNMA, dentre os quais estão: a racionalização do uso da água, do solo, do subsolo e do ar; o planejamento e a fiscalização do uso dos recursos ambientais, e a proteção dos ecossistemas, dentre outros.

\footnotetext{
${ }^{1}$ Instituto de Ciências Biológicas e Ambientais, Universidade Santa Úrsula - USU, Rua Fernando Ferrari, 75, Botafogo, Rio de Janeiro - RJ

2 Instituto de Biociências, Universidade Federal do Estado do Rio de Janeiro - UNIRIO, Av. Pasteur, 458, sala 309, Urca, CEP 20290-240, Rio de Janeiro - RJ, Brasil, E-mail: 1moraes@ unirio.br
} 
Outro marco importante do Direito ambiental brasileiro foi o Art. 225 do Cap. VI da Constituição Federal de 1988 do Meio Ambiente, o qual diz que

"Todos têm direito a um ambiente ecologicamente equilibrado, bem de uso comum do povo e essencial à sadia qualidade de vida, impondo-se ao poder público e à coletividade o dever de defendê-lo e preservá-lo para as presentes e futuras gerações".

Ao longo dos anos, a crescente degradação ambiental, resultado de constante e profunda ação antropogênica, tornou-se foco central nas discussões de conferências e encontros internacionais para o meio ambiente. A questão ambiental passou a ser vista, cada vez mais, como um elemento essencial a ser considerado no processo de gestão (GOBBI; BRITTO, 2005).

Estima-se que dois bilhões de hectares de solo estão degradados devido à atividade humana, área maior que os Estados Unidos e o México juntos, e que muitas espécies estão ameaçadas de extinção devido à degradação de habitats e a outras causas (CASSARA et al., 2002). Cerca de 150 mil quilômetros quadrados de corais estão em risco de degradação entre médio e alto, e esse problema pode ser agravado pela mudança do clima e pela elevação da temperatura dos mares (VILELA JÚNIOR; DEMAJOROVIC, 2006).

Segundo Donaire (1999), a questão ambiental é uma realidade que chegou definitivamente às empresas modernas e a implantação sistematizada de processos de Gestão Ambiental tem sido uma das respostas das empresas a esse conjunto de pressões.

Tinoco e Kraemer (2004) ressaltam que a crescente concorrência que o mundo vivencia, face às expectativas dos clientes, cada vez mais exigentes, não se restringe à procura de determinado nível de qualidade ao menor custo.

A informação e a consciência ambiental têm feito com que os clientes estejam cada vez mais predispostos a consumir produtos que respeitem o meio ambiente. Deste modo, fica claro que, para a empresa/indústria atingir o mercado externo e ser competitiva, deverá ter a qualidade total que só será alcançada com a Qualidade Ambiental.

O mundo coorporativo conscientizou-se de que teria de mudar seus conceitos e de que seria imprescindível demonstrar tanto a sua conformidade com a legislação ambiental como garantir o seu compromisso com o meio ambiente por meio da implantação e da manutenção de um Sistema de Gestão Ambiental (OLIVEIRA FILHO, 2004).

Dessa forma, houve a elevação das preocupações com a questão ambiental para o nível estratégico das empresas (NASCIMENTO, 2005). O mercado ingressa em um processo de conscientização ecológica e adota mecanismos limpos, como selos verdes e normas, como a série ISO 14000 , que passam a constituir atributos desejáveis, não somente para a aceitação e as compras de produtos e serviços, como também para a construção de uma imagem ambientalmente positiva junto à sociedade.

As organizações são pressionadas a modernizarem seus sistemas de gestão para que proporcionem maior qualidade de produtos, viabilizem e suportem inovações tecnológicas, contribuam com o desenvolvimento sustentável, garantam o aumento da competitividade e, consequentemente, da lucratividade (OLIVEIRA; PINHEIRO, 2010, p. 51).

Para auxiliar as empresas/indústrias a tomarem decisões, existem vários métodos em que se aplicam múltiplos critérios (MCDA), utilizando diferentes abordagens para enfrentar as dificuldades encontradas na vida real (TERVONEN; FIGUEIRA, 2008). Decisões permeiam todas as atividades humanas, seja em nível pessoal, seja em nível organizacional, e muitas dessas decisões são tomadas de maneira informal ou intuitiva (MEIRELLES; GOMES, 2009). No entanto, ao longo dos tempos, a necessidade de melhores decisões levou à busca de abordagens sistemáticas e estruturadas que conduzissem a um processo decisório mais satisfatório (MEIRELLES; GOMES, 2009).

O estudo apresenta uma avaliação multicritério em uma filial de empresa multinacional de origem holandesa, que trabalha no segmento de soluções temporárias de energia e sistemas de controle de temperatura. A filial nacional ainda não possui uma certificação ambiental e nem um SGA implantado.

Os principais objetivos deste trabalho são: i) avaliar alguns impactos provenientes das atividades da filial da empresa multinacional; ii) apresentar alternativas e critérios visando minimizar ou mitigar os problemas ambientais identificados; iii) utilizar o método multicritério (TODIM) para hierarquizar as alternativas prioritárias na opinião de alguns funcionários de diferentes setores da empresa. A avaliação multicritério foi utilizada para servir como subsídio para a implantação na filial nacional de um Sistema de Gestão Ambiental baseado na norma ISO 14001.

\section{Métodos}

\subsection{Coleta de informações}

As informações foram obtidas na internet, em acervos bibliográficos e por meio de entrevistas 
com dez funcionários da empresa em questão, pertencentes a distintos departamentos, dentre os quais: Qualidade, Saúde, Meio Ambiente e Segurança (QSMS), marketing, financeiro, operacional e a alta administração.

\subsection{Método Tomada de Decisão Interativa Multicritério - TODIM}

O método escolhido para o trabalho foi o TODIM (Tomada de Decisão Interativa Multicritério) (GOMES; GOMES; ALMEIDA, 2002; GOMES; RANGEL, 2009). O auxílio multicritério baseado no processo analítico hierárquico (SAATY, 1980) é um método de avaliação de impactos que se utiliza de cálculos matemáticos e apoia pessoas e organizações para tomarem decisões sob a influência de uma multiplicidade de critérios. A aplicação do método depende da escolha das alternativas de solução de problemas, muitas vezes complexos (GOMES et. al., 2004), e dos respectivos critérios ou objetivos a serem atingidos pelas alternativas. O método TODIM foi utilizado por ser facilmente compreendido mesmo por profissionais que não possuam uma base sólida em álgebra linear; possibilita, ainda, analisar critérios quantitativos e qualitativos; classifica os critérios hierarquicamente, e lida com a interdependência dos critérios (RANGEL; GOMES; MOREIRA, 2009).

Os atores escolhidos para a avaliação das matrizes devem ser conhecedores do assunto ou terem, de alguma forma, vivenciado o problema, para evitar ao máximo a subjetividade dos resultados, para obtenção de um julgamento o mais realista possível.

O método multicritério vem sendo utilizado em avaliações de impactos ambientais, provenientes de diferentes atividades humanas: tratamento e destino final de esgotos domésticos e industriais em lagunas costeiras (MORAES; OHAYON; GOMES, 1994); aterros controlados (MARMELLO; MORAES, 2007); projetos para gerenciamento de recursos hídricos (CHOWDHURY; RAHMAN, 2008), nos quais se requerem tomadas de decisão com múltiplos critérios, envolvendo diferentes opiniões e interesses.

\subsection{Elaboração das matrizes}

Para a aplicação do método multicritério, foram elaboradas duas matrizes, sendo a primeira de valoração das alternativas em relação aos critérios ou objetivos (Tabela 1) e a segunda, para valorar os critérios entre si (Tabela 2).

Os pesos das alternativas em relação aos critérios foram definidos entre 0 e 5 , em que:

- A alternativa $i$ não possui nenhuma importância para o critério $y$;

- A alternativa $i$ possui pouca importância para o critério $y$;
- A alternativa $i$ possui razoável importância para o critério $y$;

- A alternativa $i$ é importante para o critério $y$;

- A alternativa $i$ é muito importante para o critério $y$;

- A alternativa $i$ possui absoluta importância para o critério $y$.

Da mesma forma, os critérios foram valorados entre si, em uma matriz triangular, na qual:

- o critério $x$ possui a mesma importância que o critério $y$;

- o critério $x$ é duas vezes mais importante que o critério $y$;

- o critério $x$ é três vezes mais importante que o critério $y$.

Para a priorização das alternativas de solução, foram obedecidas as etapas abaixo (a-f), utilizadas para a aplicação do método TODIM (GOMES; LIMA, 1992; GOMES; RANGEL, 2009). Os cálculos referentes ao método foram realizados no programa Excel.

- Valoração das alternativas em relação aos critérios (Tabela 1) a partir do julgamento de valor expresso em uma escala de 0 a 5;

- Normalização da matriz de unidades parciais (1), de modo que cada alternativa seja o valor de uma unidade da escala do referido critério, em que (Equação 1):

$$
0 \leq \text { Wic } \leq 1
$$

- Comparação entre os pares de critérios definidos na matriz triangular (Tabela 2), utilizada para uma estimativa de contribuição relativa de determinado critério ao objetivo global do processo de tomada de decisão, quando comparado a outro critério;

- Determinação do critério de referência, a partir da soma vertical dos elementos da matriz triangular e da normalização por meio da divisão pelos valores obtidos;

- Determinação da matriz de dominância, a partir da expressão matemática (Equação 2):

$$
\delta(i, j)=\sum_{c=1}^{m}\left[a_{c r}\left(W_{i c}-W_{j c}\right)\right]
$$

- Cálculo da medição dos valores globais e priorização de cada alternativa por meio da Equação (3):

$$
\xi=\frac{\sum_{j=1}^{n} \delta(i, j)-\operatorname{Min}_{i} \sum_{j=1}^{n} \delta(i, j)}{\operatorname{Máx}_{i}^{n} \sum_{j=1}^{n} \delta(i, j)-\operatorname{Min}_{i}^{n} \sum \delta(i, j)}
$$

em que:

$a_{\mathrm{cr}}=$ taxa de substituição do critério genérico

(c) pelo de referência (r); 
Tabela 1. Matriz de Alternativas e Critérios.

\begin{tabular}{|c|c|c|c|c|c|c|c|c|c|c|}
\hline Alternativas & C1 & $\mathbf{C 2}$ & C3 & $\mathrm{C4}$ & C5 & C6 & C7 & C8 & C9 & C10 \\
\hline 1) Instalar filtros ou catalisadores nos geradores & & & & & & & & & & \\
\hline $\begin{array}{l}\text { 2) Fornecer aos funcionários canecas, copos, } \\
\text { garrafas e sacolas reutilizáveis, buscando } \\
\text { evitar o uso excessivo de plásticos }\end{array}$ & & & & & & & & & & \\
\hline $\begin{array}{l}\text { 3) Armazenar os resíduos perigosos (em tambores), para } \\
\text { evitar o transborde dos resíduos }\end{array}$ & & & & & & & & & & \\
\hline $\begin{array}{l}\text { 4) Implantar programa de educação ambiental, para evitar } \\
\text { desperdícios e informar/conscientizar os funcionários }\end{array}$ & & & & & & & & & & \\
\hline $\begin{array}{l}\text { 5) Instalar descargas a vácuo e realizar } \\
\text { controle de vazamentos }\end{array}$ & & & & & & & & & & \\
\hline $\begin{array}{l}\text { 6) Elaborar plano para contenção de derrames capaz de } \\
\text { conter a quantidade total de combustível nos tanques }\end{array}$ & & & & & & & & & & \\
\hline $\begin{array}{l}\text { 7) Realizar inspeções semanais nos tanques de } \\
\text { combustível dos geradores a diesel }\end{array}$ & & & & & & & & & & \\
\hline $\begin{array}{l}\text { 8) Implantar um sistema de coleta seletiva, para } \\
\text { aproveitamento dos resíduos gerados pela empresa }\end{array}$ & & & & & & & & & & \\
\hline $\begin{array}{l}\text { 9) Instalar sensores de movimento nas luzes e monitorar o } \\
\text { medidor de eletricidade para constatar diminuição }\end{array}$ & & & & & & & & & & \\
\hline $\begin{array}{l}\text { 10) Implantar campanha incentivando a redução } \\
\text { do uso de papel e maximizar o uso de e-mail }\end{array}$ & & & & & & & & & & \\
\hline
\end{tabular}

Tabela 2. Matriz de Critérios vs. Critérios.

\begin{tabular}{|c|c|c|c|c|c|c|c|c|c|c|}
\hline Critérios & C1 & $\mathrm{C2}$ & C3 & $\mathrm{C4}$ & C5 & C6 & C7 & C8 & C9 & C10 \\
\hline 1) Reduzir o consumo de eletricidade & & & & & & & & & & \\
\hline 2) Minimizar o uso de papéis utilizados no trabalho & & & & & & & & & & \\
\hline 3) Reduzir o consumo de água & & & & & & & & & & \\
\hline 4) Reduzir o uso de materiais plásticos & & & & & & & & & & \\
\hline 5) Reduzir o risco de derrames de combustível & & & & & & & & & & \\
\hline 6) Reduzir a emissão de $\mathrm{CO}_{2}$ e $\mathrm{CO}$ & & & & & & & & & & \\
\hline 7) Reciclar os resíduos (recicláveis) gerados pelo Depot & & & & & & & & & & \\
\hline 8) Prevenir o vazamento de resíduos perigosos & & & & & & & & & & \\
\hline $\begin{array}{l}\text { 9) Conscientizar os colaboradores da empresa sobre as } \\
\text { questões ambientais }\end{array}$ & & & & & & & & & & \\
\hline 10) Prevenir a contaminação dos solos e dos recursos hídricos & & & & & & & & & & \\
\hline
\end{tabular}

$\delta(i, j)=$ medida de dominância da alternativa $i$ em relação à alternativa $j$;

Se $\delta(i, j)<0$, diz-se que a alternativa $i$ domina a alternativa $j$

$W_{\text {ic }}$ e $W_{\text {jc }}=$ valor mensurado ou peso das alternativas $i$ e $j$ em relação ao critério c; $\xi=$ valor global da alternativa.

\section{Fundamentação teórica}

\subsection{Desenvolvimento sustentável}

O conceito de desenvolvimento sustentável surgiu em 1980 pela necessidade de conciliar o desenvolvimento econômico com a redução do impacto ambiental, e foi consagrado em 1987, na Comissão Mundial sobre Meio Ambiente, com a publicação do relatório final da Comissão, O Nosso Futuro Comum, que ficou conhecido por Relatório Brundtland. Nesse relatório, o termo "desenvolvimento sustentável" foi definido como "[...] o desenvolvimento que dê resposta às necessidades do presente, sem comprometer a possibilidade de as gerações futuras darem resposta às suas próprias necessidades" (COMISSÃO..., 1988, p. 46). O relatório Brundtland criticou o modelo adotado pelos países desenvolvidos por ser insustentável e impossível de ser copiado pelos países em desenvolvimento, sob pena de se esgotarem rapidamente os recursos naturais.

O desenvolvimento sustentável sugere qualidade em vez de quantidade (LÉLÉ, 1991), com a redução do uso de matérias-primas e produtos, e o aumento da reutilização e da reciclagem. Segundo Sachs (2002), para que o equilíbrio entre tecnologia e ambiente seja 
alcançado, a proteção do ambiente tem de ser entendida como parte integrante do processo de desenvolvimento e não pode ser considerada isoladamente. Em outras palavras, o desenvolvimento sustentável depende do planejamento e do reconhecimento de que os recursos naturais são finitos (ANDRADE; TACHIZAWA; CARVALHO, 2000). Este é um conceito que representa uma nova forma de desenvolvimento econômico, que leva em conta o meio ambiente (BECKER et al., 1999).

\subsection{International Organization for Standardization - ISO 14000}

As normas da Série ISO 14000 foram desenvolvidas pelo Comitê Técnico 207 da International Organization for Standardization. Trata-se de um grupo de normas que fornece ferramentas e estabelece um padrão de Sistema de Gestão Ambiental, abrangendo seis áreas bem definidas (MOREIRA, 2001): Sistemas de Gestão Ambiental (Série ISO 14001 e 14004); Auditorias Ambientais (ISO 14010, 14011, 14012 e 14015); Rotulagem Ambiental (Série ISO 14020, 14021, 14021 e 14025); Avaliação de Desempenho Ambiental (Série ISO 14031 e 14032); Avaliação do Ciclo de Vida de Produto (Série ISO 14040, 14041, 14042 e 14043), e Termos e Definições (Série ISO 14050). No Brasil, a Associação Brasileira de Normas Técnicas (ABNT) oficializou as NBR5 ISO: a) 14001; b) 14004 ; c) 14010 ; d) 14011 e, e) 14040 . Destas, a NBR Série ISO 14001/1996 trata dos requisitos para implementação do Sistema de Gestão Ambiental (REIS, 1995; SILVA et al., 2003).

A Norma NBR Série ISO 14001 (ASSOCIAÇÃO..., 2004) especifica as principais exigências para a implantação e a adoção de um sistema de gestão ambiental (TACHIZAWA, 2002), orientando a empresa na elaboração da política ambiental e no estabelecimento de estratégias, objetivos e metas, levando em consideração os impactos ambientais significativos e a legislação ambiental em vigor no País (INTERNATIONAL..., 2004).

Em suma, as normas contidas na Série ISO 14000 são dirigidas para a organização e para o produto. As normas dirigidas para o produto dizem respeito à determinação dos impactos ambientais de produtos e serviços, ciclo de vida, rotulagem e declarações ambientais (MEYSTRE, 2003). As norrmas dirigidas para a organização proporcionam um abrangente guia para o estabelecimento, a manutenção e a avaliação de um sistema de gestão ambiental (MEYSTRE, 2003; REIS; QUEIROZ, 2004.).

\subsection{Sistema de gestão ambiental}

Uma das formas de gerenciamento ambiental de maior adoção pelas empresas tem sido a implementação de um sistema de gestão ambiental (NICOLELLA; MARQUES; SKORUPA, 2004), segundo as normas internacionais série ISO 14000, visando à obtenção de uma certificação. Esse instrumento contribui para que as empresas conheçam melhor seus processos produtivos e administrativos. Segundo Valle (2002), um dos méritos da norma ISO 14001 é a uniformização das rotinas e dos procedimentos necessários para uma organização certificar-se ambientalmente, cumprindo um roteiro padrão de exigências válido internacionalmente. Dessa forma, tem-se a possibilidade de identificar as práticas que não seguem o princípio de desenvolvimento sustentável (BATISTA et al., 2002).

Desde meados da década de 1970, vem ocorrendo a introdução progressiva de um novo cargo ou de uma nova função na estrutura das organizações: o "responsável pelo meio ambiente" ou o "serviço ambiental". Groenewegen e Vergragt (1991) relembram as modificações da atividade e de seu papel desde então:

- Antes de 1980, o tamanho dos departamentos era reduzido e suas atividades focalizavam essencialmente a evolução da regulamentação e a produção de diversos documentos, atestando os esforços realizados pela empresa (relatórios de ecotoxicologia, declarações e demandas de autorização, etc.). As atribuições do responsável pelo departamento ambiental envolviam a busca da conformidade com as normas ou com quaisquer outros dispositivos de regulamentação ambiental;

- Durante a década de 1980, as atividades dos departamentos se orientaram progressivamente para a elaboração de programas de prevenção, com a formação de pessoal, a avaliação das diferentes unidades ou setores de atividade. A responsabilidade dos membros da equipe ambiental se estendia à aplicação de medidas internas e de proteção;

- Desde o final da década de 1980, a atenção do departamento ambiental é voltada às possibilidades de desenvolvimento em torno das questões ambientais. A busca de oportunidades estratégicas e a elaboração de políticas ambientais proativas são centrais nas atividades do departamento. Os responsáveis e a equipe ambiental se inserem na estrutura decisória e influenciam progressivamente as escolhas estratégicas e de desenvolvimento tecnológico da firma; e

- A partir de meados da década de 1990, pode-se caracterizar uma nova fase histórica da integração da gestão ambiental em organizações industriais. Nesta nova fase, algumas características se destacariam: a) a introdução progressiva de uma 
perspectiva de sustentabilidade; b) a proliferação dos engajamentos coletivos, como os códigos de conduta, os convênios e os acordos voluntários; c) a maior interação entre as esferas pública e privada, com a participação dessas organizações na formulação de objetivos e na escolha de instrumentos de política ambiental, e d) o maior envolvimento da sociedade civil organizada, como, por exemplo, por meio das organizações não governamentais.

Dentro da responsabilidade social, são incluídas diversas obrigações e, entre elas, a de proteção ambiental. Ribeiro (1998), os investidores estão cada vez mais cientes de que a má postura das empresas, em relação às questões ambientais, pode colocar em risco o retorno das aplicações de recursos.

A satisfação dessa postura da empresa agrada ao publico externo e também aos seus segmentos internos, como colaboradores e acionistas (OLIVEIRA FILHO, 2004, p. 2).

\section{Estudo de caso}

\subsection{Empresa Aggreko}

A Empresa Aggreko atende a pedidos de caráter emergencial ou programado, em qualquer lugar onde haja demanda energética, seguindo uma rotina de análise, planejamento, implementação, comissionamento e operação de serviços.

A Empresa Aggreko Brasil é uma filial nacional e ainda não possui uma certificação ambiental e nem um SGA implantado. Está situada em Macaé, no Estado do Rio de Janeiro. Seus produtos são geradores a diesel ou a gás, chillers, ar condicionado, torres de resfriamento e bancos de carga de alta ou baixa tensão.

A Aggreko Europa, mais especificamente o Depot de Dumbarton na Escócia, possui a certificação ambiental da ISO 14001:2004. A empresa se organiza em negócios locais denominados Depots (Depósitos) e também na área de Projetos. Cada Depot possui sua própria certificação, seja esta do Sistema de Qualidade (ISO 9001), seja do SGA (ISO 14001).

Embora ainda não possua todos os seus Depots certificados no SGA, a empresa possui uma política global de saúde, segurança e meio ambiente. Por isso, seus equipamentos são desenhados e desenvolvidos de acordo com as mais rígidas leis ambientais. Os princípios deste sistema são utilizados por todos os Depots certificados no SGA e estão documentados no Manual de Operações Global do Sistema de Gerenciamento Ambiental, elaborado pela companhia com o intuito de definir suas atividades relacionadas ao meio ambiente. Tal sistema é apoiado também por procedimentos documentados e, quando requerido, fornece instruções mais específicas.

O Manual de Operações possui a política, os objetivos, as metas, os processos, os registros, os formulários para reporte e os planos de contenção de emergência. A seguir, são enumerados alguns princípios seguidos pela empresa para garantir um gerenciamento ambiental eficaz.

\subsection{Princípio da política ambiental}

\section{A) Política ambiental, de saúde e segurança}

Como já mencionado, a organização possui uma política global de Saúde, Segurança e Meio Ambiente. Esta política reflete os objetivos gerais e o comprometimento da empresa com o meio ambiente, sendo revisada periodicamente para assegurar que continua relevante e apropriada para a organização.

\subsection{Princípio do planejamento}

\section{A) Aspectos e impactos ambientais}

A identificação das atividades do Depot de Dumbarton que podem causar danos ambientais é feita por meio do levantamento dos aspectos e impactos. Após o levantamento e a análise, uma matriz é elaborada estabelecendo as medidas e as ações necessárias, que serão tomadas para poder mitigar e, quando possível, neutralizar os impactos.

\section{B) Requisitos legais e outros}

Todo o acompanhamento dos requisitos legais aplicáveis ao negócio da Aggreko no Depot de Dumbarton é feito pelo Gerente de Saúde, Segurança e Meio Ambiente responsável, por meio do acesso a websites apropriados ou de contato regular com as autoridades relevantes. Esta relação de requisitos legais é mantida no Depot e uma cópia é administrada pelo departamento de QHSE.

\section{C) Objetivos, metas e programas}

Além das metas ambientais globais da empresa que são acordadas na Reunião Global de HSE, para o ano subsequente, o Depot em questão estabelece suas metas ambientais locais que também são definidas em reuniões anuais por membros da alta direção (gerente do Depot, gerente de QHSE e responsáveis por cada área). O desempenho das metas globais é revisto pelo menos uma vez ao ano durante a reunião de análise crítica da direção e também durante a Reunião Global de HSE, sendo colocadas novas metas para o ano seguinte, quando apropriado. O mesmo se aplica para as metas locais do Depot de Dumbarton, porém estas são revistas pela alta direção do Depot.

Em seu SGA, a empresa estabeleceu três principais Indicadores de Desempenho, que foram padronizados utilizando os seguintes critérios: 
- Universalmente compreendido e significativo para os clientes e negócios da empresa;

- Específicos para os negócios da empresa, especialmente áreas de grandes riscos;

- Medição da eficácia do SGA;

- Medição da capacidade da empresa de controlar os aspectos ambientais.

Os três indicadores são:

- Taxa de liberação de petróleo;

- Redução no consumo de energia;

- Redução e reciclagem do uso de papel.

\subsection{Princípio da implementação e operação}

\section{A) Estrutura e responsabilidade}

A Aggreko possui uma estrutura global que identifica as responsabilidades e autoridades para o gerenciamento seguro do meio ambiente em nível global, assim como um organograma de responsabilidades organizacional de cada localidade.

\section{B) Treinamento, conscientização e competência}

Mensalmente, treinamentos básicos de HSE são fornecidos para os funcionários do Depot pelo Departamento de QHSE. O Gerente local ou representante de QHSE apresenta o material com temas relacionados a saúde, segurança e meio ambiente. Tais treinamentos são registrados e listas de presença, que são mantidas na localidade, são enviadas ao RH para o controle de treinamento.

\section{C) Comunicação}

Para comunicação interna do SGA, são elaborados relatórios diários que monitoram o desempenho, por meio de reuniões regulares registradas em atas, havendo ainda orientação especial, avisos gerais, e-mails, boletins e ARC (Aggreko Resource Center). Qualquer comunicado verbal em relação às questões ambientais recebidas de membros da equipe é registrado e enviado ao Gerente de HSE local para aplicação das medidas adequadas. O acesso ao SGA do Depot é disponibilizado através do ARC.

A comunicação geral com a mídia e com o público é de responsabilidade exclusiva do Departamento de Mídia.

\section{D) Documentação}

A Aggreko estabeleceu um SGA documentado aplicável a todos os Depots certificados, que atende às exigências da ISO 14001:2004. O sistema compreende a política, os objetivos, metas, manuais, processos, registro de aspectos, formulários e planos de emergência.

\section{E) Controle de documentos}

O SGA do Depot de Dumbarton é revisado pela alta direção do departamento de QHSE e aprovado pelo Diretor Regional.

\section{F) Controle operacional ambiental}

Concomitantemente ao SGA do Depot, são incluídas atividades para controlar impactos ambientais identificadas no manual das Melhores Práticas Operacionais (Best Operating Practices - BOP) da organização.

Segundo o Sistema de Gestão Ambiental do Depot em questão, somente companhias registradas para manusear resíduos estão aprovadas como fornecedores para coletar e eliminar quaisquer resíduos perigosos gerados, com comprovação documentada mantida na localidade.

As seguintes medidas são planejadas e implantadas nos equipamentos fornecidos pela Aggreko Europa:

- Unidades de Redução Catalítica Seletiva (SCR) e filtros de matéria particulada são usados quando exigências contratuais e/ou legais indicarem tal aplicabilidade;

- Reciclagem de produtos de petróleo e filtros de resíduos sólidos;

- Uso de tanques de armazenagem de combustível com casco duplo, quando possível;

- Uso de contenção quando cascos duplos não forem viáveis, para instalações terrestres;

- Uso de áreas de contenção dentro dos geradores para minimizar a poluição local;

- Programa de manutenção de refrigerantes em equipamentos de controle de temperatura;

- Programa de manutenção para minimizar a emissão de $\mathrm{CO}_{2}$ na atmosfera.

A manutenção de equipamentos, como aparelhos de ar condicionado e máquinas de fotocópia, é executada por empresas contratadas autorizadas e competentes.

Todos os funcionários que conduzem veículos da companhia são encorajados a guiar veículos de baixa taxa de emissão, planejar reuniões/visitas de forma a reduzir milhagem e queima de combustível, mantendo intervalos regulares de manutenção.

\subsection{Preparação e atendimento a emergências}

Assim como definido pelo seu SGA, o presente Depot possui um Plano de Contingência Ambiental e um Plano de Resposta a Emergência estabelecidos e compreendidos por seus funcionários e pelas empresas que trabalham a serviço da Aggreko. Esses planos delineiam as medidas a serem seguidas pela empresa, sendo requeridos por aqueles que a contatarem em caso de algum vazamento ou outra emergência ambiental, 
como também para as companhias de remediação a serem contratadas como terceirizadas.

\subsection{Princípio da verificação e ação corretiva}

\section{A) Monitoramento e medição}

Para a realização do monitoramento e medição, há um procedimento documentado que foi estabelecido e implementado em relação à coleta e à análise de dados.

\section{B) Avaliação de conformidade}

Os Gerentes de HSE avaliam a conformidade com os requisitos legais de Saúde, Segurança e Meio Ambiente, e quaisquer códigos de práticas relevantes continuamente.

\section{C) Não conformidade e ações corretivas e preventivas}

Auditorias, reclamações, comunicados, alterações em exigências legais e outras referentes aos aspectos ambientais significativos podem incorrer em medidas preventivas e corretivas.

\section{D) Controle de registros}

Os registros de atividades de HSE do Depot são mantidos de maneira legível e adequada a critério do Gerente Regional de HSE, para demonstrar a conformidade com os requisitos da ISO 14001:2004 e regulamentos associados. Os registros relevantes são especificados em procedimentos individuais e, exceto quando definido em contrário, são mantidos por um período mínimo de três anos.

\section{E) Auditoria interna}

No Depot, são realizadas auditorias internas padronizadas que refletem sua capacidade geral de cumprir com o SGA. O processo da auditoria interna consiste em uma pontuação, medidas corretivas, acompanhamentos e relatórios. O departamento de HSE da empresa oferece os recursos e as ferramentas necessárias para assegurar a capacitação técnica e as condições necessárias que permitam o cumprimento das auditorias. Existem três tipos de listas de verificação (checklist): uma que é abrangente e utilizada pelo Departamento de QHSE para auditorias anuais ou semestrais; a segunda, que possui 20 itens a serem verificados e é preenchida pelo representante local de QHSE trimestralmente, e a terceira, que possui dez itens e é usada localmente como meio de autoauditoria e concentra-se na identificação dos riscos de HSE.

\subsection{Princípio da análise crítica}

\section{A) Revisão administrativa}

A revisão administrativa é parte integral do SGA de Dumbarton e ocorre pelo menos uma vez ao ano. A equipe de revisão compõe-se assim: o Diretor Regional, o Gerente de Serviço Regional e o Gerente de HSE Regional.

Todos esses princípios do Sistema de Gestão Ambiental seguidos pela Aggreko de Dumbarton buscam a execução de serviços em conformidade com o meio ambiente. Para isso, a empresa realiza testes que priorizam o fator ambiental, viabilizando uma maior competitividade e qualidade ambiental. A sua atuação na área ambiental abrange quatro áreas principais: eficiência energética; combustíveis alternativos; qualidade do ar e do solo, e ruído.

Tal sistema auxilia na conservação ambiental, pois, além de abonar que os requisitos legais aplicáveis ao meio ambiente sejam cumpridos, também sujeita a empresa a avaliar, controlar e/ou eliminar e monitorar os impactos ambientais decorrentes de suas atividades.

\section{Aplicação do método Tomada de Decisão Interativa Multicritério - TODIM}

A aplicação do método TODIM foi realizada tendo como caso de estudo a filial nacional da empresa Aggreko, que carece de um sistema de gestão ambiental, no sentido de subsidiar a implantação de uma gestão ambiental na empresa. Foram selecionadas dez alternativas e dez critérios em função da opinião de dez entrevistados, funcionários da filial Aggreko Brasil.

Todos os atores selecionados foram solícitos em valorar as matrizes e consideraram certo grau de preocupação ambiental ao priorizar as alternativas propostas. A priorização das alternativas em relação às diferentes opiniões (Tabela 3) apontou a alternativa A4 - implantação de um programa de educação ambiental - como a principal pela maioria dos atores, mostrando que existe uma conscientização e que algumas mudanças devem ser realizadas, quando se requer um comprometimento ambiental. A alternativa A6 - elaborar plano de contenção de derrames - ficou em segundo lugar, escolhida por cinco atores que identificaram que essa alternativa é primordial para evitar riscos ao meio ambiente, uma vez que alguns produtos utilizados pela empresa oferecem perigo à biota e aos seres humanos. Em terceiro lugar, ficou a alternativa $\mathrm{A} 10$ - implantar campanha incentivando a redução do uso de papel. E, em quarto lugar, 
Tabela 3. Priorização e valores globais das alternativas.

\begin{tabular}{|c|c|c|c|c|c|c|c|c|c|}
\hline \multicolumn{2}{|c|}{ Atores } & $\mathbf{C F}$ & DR & $\mathbf{M}$ & MC & S-QHSE & $\mathrm{CM}$ & $\mathrm{CO}$ & C-QHSE \\
\hline \multirow[t]{2}{*}{ A1 } & VG\% & 27,34 & 33,90 & 27,63 & 27,37 & 37,49 & - & - & 4,49 \\
\hline & $\mathrm{P}$ & 4 & 4 & 7 & 6 & 8 & & & 9 \\
\hline \multirow[t]{2}{*}{ A2 } & VG\% & 5,76 & 10,17 & 52,49 & - & 47,14 & 26,51 & 19,86 & 15,50 \\
\hline & $P$ & 7 & 7 & 5 & & 7 & 7 & 5 & 7 \\
\hline \multirow[t]{2}{*}{ A3 } & VG\% & 14,39 & 33,90 & 55,51 & 29,47 & 47,70 & 52,68 & 24,37 & 29,47 \\
\hline & $\mathrm{P}$ & 6 & 4 & 4 & 5 & 6 & 5 & 4 & 4 \\
\hline \multirow[t]{2}{*}{ A4 } & VG\% & 100,00 & 100,00 & 100,00 & - & 92,38 & 100,00 & 100,00 & 100,00 \\
\hline & $\mathrm{P}$ & 1 & 1 & 1 & & 2 & 1 & 1 & 1 \\
\hline \multirow[t]{2}{*}{ A5 } & VG\% & - & 20,34 & - & - & - & 11,85 & 0,68 & 12,24 \\
\hline & $\mathrm{P}$ & & 6 & & & & 9 & 9 & 8 \\
\hline \multirow[t]{2}{*}{ A6 } & VG\% & 14,39 & 61,02 & 66,95 & 67,37 & 60,36 & 79,38 & 23,29 & 46,87 \\
\hline & $\mathrm{P}$ & 6 & 2 & 2 & 2 & 5 & 2 & 4 & 2 \\
\hline \multirow[t]{2}{*}{ A7 } & VG\% & 38,49 & 44,92 & 38,46 & 100,00 & 60,36 & 52,21 & 4,33 & 43,43 \\
\hline & $\mathrm{P}$ & 2 & 3 & 6 & 1 & 5 & 6 & 7 & 3 \\
\hline \multirow[t]{2}{*}{ A8 } & VG\% & 20,14 & - & 56,92 & 31,58 & 66,50 & 22,76 & 3,29 & 23,66 \\
\hline & $\mathrm{P}$ & 5 & & 3 & 4 & 4 & 8 & 8 & 6 \\
\hline \multirow[t]{2}{*}{ A9 } & VG\% & 3,24 & 3,39 & 12,31 & 31,58 & 100,00 & 61,51 & 5,42 & - \\
\hline & $\mathrm{P}$ & 8 & 8 & 9 & 4 & 1 & 3 & 6 & \\
\hline \multirow[t]{2}{*}{ A10 } & VG\% & 30,58 & 27,12 & 14,77 & 46,32 & 90,04 & 61,04 & 24,95 & 25,29 \\
\hline & $\mathrm{P}$ & 3 & 5 & 8 & 3 & 3 & 4 & 2 & 5 \\
\hline
\end{tabular}

Alternativas (A1-A10); Valor Global (VG); Priorização (P). CO-Coordenador operacional; DR-Diretor Regional; M-Marketing; MC-Melhoria Contínua; CM-Country Manager; CF-Coordenador Financeiro; S-QHSE-Supervisora de QHSE; C-QHSE-Coordenador de QHSE.

ficaram as alternativas A7 e A8, realizar inspeções semanais nos tanques de combustível dos geradores a diesel e implantação de sistema de coleta seletiva, respectivamente. A priorização mostrou que houve divergências na escolha do terceiro lugar, mas, por outro lado, denotou que os atores escolhidos para a valoração estão preocupados com a economia de materiais utilizados na empresa e a redução de resíduos gerados no ambiente que podem trazer riscos. Ao mesmo tempo, mostrou-se que, a partir da conscientização/educação, pode haver uma mudança de atitude favorecendo tanto a empresa como o meio ambiente.

\section{Conclusão}

Ao finalizar este estudo, foi concluído que a certificação ambiental obtida pela Aggreko de Dumbarton oferece benefícios para a conservação do meio ambiente, bem como para a própria empresa de diversas formas. Em relação à empresa, o maior de todos os benefícios está relacionado à opinião que o público tem da mesma, tornando-se um diferencial de competitividade por ampliar as oportunidades de negócio, por meio de uma imagem verde/limpa. Já o benefício ambiental provém das diversas maneiras que uma corporação procura minimizar seu impacto no meio ambiente e, ao mesmo tempo, conscientizar seus funcionários para agirem em prol da conservação ambiental por meio de treinamentos, programas, ações ambientais, etc. Portanto, para continuar concorrendo em mercados cada vez mais competitivos, as empresas necessitam tomar conhecimento dos problemas ambientais decorrentes de seus processos produtivos e buscar soluções limpas, eficazes e eficientes. Caso contrário, perderão gradativamente seu espaço entre os consumidores mais exigentes e preocupados com o meio ambiente.

Em relação ao método multicritério, sua aplicação foi eficaz para mostrar alguns pontos fracos e fortes na filial da empresa nacional e, ao mesmo tempo, direcionar certas ações, que afligem os funcionários. Nesse sentido, é um método que pode subsidiar tomadas de decisão auxiliando na gestão ambiental da empresa, por meio da redução do consumo e do desperdício de materiais, e do gasto em energia. $\mathrm{O}$ uso do método TODIM possibilita a interatividade entre os indivíduos e grupos envolvidos no processo decisório, gerando o comprometimento de todos. Deste modo, pode-se promover uma gestão democrática, a partir de soluções conjuntas que envolvam equipes multidisciplinares de profissionais e de grupos de interesse, embora cada um com o seu ponto de vista em relação ao problema e que, muitas vezes, este se mostre conflituoso em relação ao ponto de vista dos demais. Ainda, é uma medida estratégica de solução, pois focaliza pontos da problemática a serem resolvidos prioritariamente.

$\mathrm{O}$ uso do método mostrou que os critérios e alternativas podem estar interligados, sendo, 
portanto, interdependentes. Nesse caso, a solução do problema depende de mais de uma alternativa. Assim, é necessário ter cautela ao escolher os atores que irão participar da valoração, já que os mesmos devem conhecer ou vivenciar os problemas em questão e, ao mesmo tempo, apontar alternativas e critérios bem embasados para que não haja dúvidas ou sobreposições.

\section{Agradecimentos}

À empresa Aggreko e a todos os seus membros, que valoraram as matrizes, tornando possível a aplicação do método: Diógenes Paoli, Danilo Lopez, Fernanda Mattos, Guilherme Marinhos, Iris Alencar, José Schiavi, Julio Temen e Omar Peres.

\section{Referências}

ANDRADE, R. O. B.; TACHIZAWA, T.; CARVALHO, A. B. Gestão ambiental: enfoque estratégico aplicado ao desenvolvimento sustentável. 2. ed. São Paulo: Makron Books, 2000. 256 p.

ASSOCIAÇÃO BRASILEIRA DE NORMAS TÉCNICAS ABNT. ISO 14001: Sistemas da Gestão ambiental: requisitos com orientações para uso. Rio de Janeiro: ABNT, 2004.

BATISTA, A. O. et al. A questão ambiental nas organizações - Estudo de caso: Sistema de Gestão Ambiental da companhia Níquel Tocantis. São Paulo: SENAC, 2002.

BECKER, D. F. Desenvolvimento Sustentável: Necessidade e/ou possibilidade. Santa Cruz do Sul: EDUNISC, 1999. 134 p.

BRASIL. Constituição da República Federativa do Brasil de 1988. 05 out. 1988. Disponível em: $<$ http://www.planalto.gov.br/ccivil_03/constituicao/ constitui\%C3\%A7ao.htm>. Acesso em: 17 nov. 2009.

BRASIL. Presidência da República. Lei Federal 6.938, de 31 de agosto de 1981. Dispõe sobre a Política Nacional do Meio Ambiente, seus fins e mecanismos de formulação e aplicação, e dá outras providências. Diário Oficial da República Federativa do Brasil, Brasília, DF, 02 set. 1981. Disponível em: <http://www.planalto.gov.br/ ccivil_03/Leis/L6938.htm>. Acesso em: 12 set. 2009.

BRASIL. Ministério do Meio Ambiente. Conselho Nacional do Meio Ambiente - CONAMA. Resolução n. 01, de 23 de janeiro de 1986. Define as situações e estabelece os requisitos e condições para desenvolvimento de Estudo de Impacto Ambiental - EIA e respectivo Relatório de Impacto Ambiental - RIMA. Diário Oficial da República Federativa do Brasil, Brasília, DF, 17 set. 1986.

CASSARA, A. et al. Tomorrow's Markets: Global Trends and their Implications for Business. Disponível em: <http://www.wri.org/publication/tomorrows-markets>. Acesso em: 12 set. 2009.

CHOWDHRY, R. K.; RAHMAN, R. Multicriteria decision analysis in water resources management: the malnichara channel improvement. International Journal of
Environment Science and Technology, v. 5 , n. 2, p. 195-204, 2008.

COMISSÃO MUNDIAL SOBRE O MEIO AMBIENTE E DESENVOLVIMENTO. Nosso Futuro Comum (Relatório Brundtland). Rio de Janeiro: FGV, 1988. p. 44-50.

CORAZZA, I. R. Gestão ambiental e mudanças da estrutura organizacional. RAE-eletrônica, v. 2, n. 2, p 1-23, 2003.

DONAIRE, D. Gestão ambiental na empresa. 2. ed. São Paulo: Atlas, 1999. 176 p.

GOBBI, B. C.; BRITO, M. J. Gestão Ambiental como Prática Social em uma Organização Produtora de Celulose. In: ENCONTRO ANUAL DA ASSOCIAÇÃO NACIONAL DE PROGRAMAS DE PÓS-GRADUAÇÃO EM ADMINISTRAÇÃO, 2005, Brasília. Anais... Brasília: ENANPAD, 2005.

GOMES, L. F. A. M.; LIMA, M. M. P. P. TODIM: Basics and application to multicriteria ranking of projects with environmental impacts. Foundations of Computing and Decision Sciences, v.16, n. 4, p.113-127, 1992 .

GOMES, L. F. A. M.; GOMES, C. F. S.; ALMEIDA, A. T. Tomada de Decisão Gerencial: Enfoque Multicritério. Rio de Janeiro: Editora Atlas, 2002.

GOMES, L. F. A. M.; GONZALEZ-ARAYA, M. C.; CARIGNANO, C. Tomada de Decisões em Cenários Complexos. Rio de Janeiro: Pioneira Thompson Learning, 2004.

GOMES, L. F. A. M.; RANGEL, L. A. D. An application of the TODIM method to the multicriteria rental evaluation of residential properties. European Journal of Operational Research, v. 193, n. 1, p. 204-211, 2009. http://dx.doi.org/10.1016/j.ejor.2007.10.046

GROENEWEGEN, P.; VERGRAGT, P. Environmental issues for treats and opportunities for technological innovation. Technology Analysis and Strategic Management, v. 3 n. 1, p. 43-55, 1991. http://dx.doi. org/10.1080/09537329108524031

INTERNATIONAL ORGANIZATION FOR STANDARDIZATION - ISO. ISO 14001: Environmental Management Systems: requirements with guidance for use. Geneva: ISO, 2004.

LÉLÉ, S. M. Sustainable development: a critical review. World Development, v. 19, n. 6, p. 607-621, 1991. http://dx.doi.org/10.1016/0305-750X(91)90197-P

MARMELLO, K. P. M. S.; MORAES, L. A. F. Método Multicritério de Apoio à Decisão na Avaliação de Impactos Ambientais: Estudo de Caso do Aterro de Gericinó. In: BARBARA, S.; FREITAS, S. Design, Gestão, Métodos, Projetos, Processos. Rio de Janeiro: Ciência Moderna, 2007. p. 73-90.

MEIRELLES, C. L. A.; GOMES, L. F. A. M. O apoio multicritério à decisão como instrumento de gestão do conhecimento: uma aplicação à indústria de refino de petróleo. Pesquisa Operacional, v. 29, n. 2, p. 451-470, 2009. http://dx.doi.org/10.1590/ S0101-74382009000200011

MEYSTRE, J. A. Acompanhamento de Implementação da Certificação Ambiental pela Norma NBR ISO 14001/96 em uma Micro-Empresa de Consultoria Ambiental. In: SEMINÁRIO ECONOMIA DO MEIO AMBIENTE, 
3., 2003. Anais... Campinas: Instituto de Economia, UNICAMP, 2003.

MORAES, L. A. F.; OHAYON, P.; GOMES, L. F. A. M. Análise dos Impactos Ambientais no Complexo Lagunar da Baixada de Jacarepaguá, utilizando-se o auxílio multicritério à decisão. Revista Unimar, v. 16, n. 3, p. 127-143, 1994.

MOREIRA, M. S. Estratégia e implantação do Sistema de Gestão Ambiental (Modelo Série ISO 14000). Belo Horizonte: Desenvolvimento Gerencial, 2001. 286 p.

NASCIMENTO, L. F. M. Gestão Socioambiental Estratégica: a Percepção de Executivos de Pequenas e Médias Empresas Americanas. In: ENCONTRO ANUAL DA ASSOCIAÇÃO NACIONAL DE PROGRAMAS DE PÓS-GRADUAÇÃO EM ADMINISTRAÇÃO, 2005, Brasília. Anais... Brasília: ENANPAD, 2005.

NICOLELLA, G.; MARQUES, F. J.; SKORUPA, A. L. Sistema de gestão ambiental: aspectos teóricos e análise de um conjunto de empresas da região de Campinas, SP. Jaguariúna: Embrapa Meio Ambiente, 2004. 42 p.

OLIVEIRA, O. J.; PINHEIRO, C. R. M. S. Implantação de sistemas de gestão ambiental ISO 14001: uma contribuição da área de gestão de pessoas. Gestão e Produção, v. 17, n. 1, p. 51-61, 2010. http://dx.doi. org/10.1590/S0104-530X2010000100005

OLIVEIRA FILHO, J. Gestão ambiental e sustentabilidade: um novo paradigma ecoeconômico para as organizações modernas. Domus On Line: Revista de Teoria Política, Social e Cidadania, v. 1, n. 1, p. 92-113, 2004. Disponível em: <http://www.fbb.br/downloads/domus_jaime.pdf>. Acesso em: 11 jun. 2009.

RANGEL, L. A. D.; GOMES, L. F. A. M.; MOREIRA, R. A. Decision theory with Multiple criteria: an application of electre IV and TODIM to Sebrae/RJ. Pesquisa
Operacional, v. 29, n. 3, p. 577-590, 2009 . http:// dx.doi.org/10.1590/S0101-74382009000300007

REIS, L. F. S. S.; QUEIROZ, S. M. P. Gestão ambiental em pequenas e médias empresas. Rio de Janeiro: Qualitymark, 2002.123 p.

REIS, M. J. L. ISO 14000 - Gerenciamento ambiental: um novo desafio para sua competitividade. Rio de Janeiro: Ed. Qualitymark, 1995. 296 p.

RIBEIRO, M. S. O Custeio por atividades aplicado ao tratamento contábil dos gastos de natureza ambiental. Caderno de Estudos, n. 19, p. 82-91, 1998.

SACHS, I. Caminhos para o desenvolvimento sustentável. 2. ed. Rio de Janeiro: Garamond, 2002. 95 p.

SAATY, T. L. The Analytic Hierarchy Process. New York: McGraw-Hill, 1980.

SILVA, V. A. R.; ALARCÓN, O. Q.; SILVA JR, H. S.; VIEIRA FILHO, O. Aproximando ISO 14001 aos objetivos ambientais públicos. In: SEMINÁRIO ECONOMIA DO MEIO AMBIENTE, 3., 2003, Anais..... Campinas: Instituto de Economia, UNICAMP, 2003.

TACHIZAWA, T. Gestão ambiental e responsabilidade social corporativa: estratégias de negócios focadas na realidade brasileira. São Paulo: Atlas, 2002. 442 p.

TERVONEN, T.; FIGUEIRA, J. R. A Survey on Stochastic Multicriteria Acceptability Analysis Methods. Journal of Multi-Criteria Decision Analysis, v. 15, n. 1-2, p. 1-14, 2008. http://dx.doi.org/10.1002/mcda.407

TINOCO, J. E. P.; KRAEMER, M. E. P. Contabilidade e Gestão Ambiental. São Paulo: Atlas, 2004. 304 p.

VALLE, C. E. Qualidade ambiental: ISO 14000. 4. ed. São Paulo: SENAC, 2002.

VILELA JÚNIOR, A.; DEMAJOROVIC, J. Modelos e ferramentas de Gestão Ambiental: Desafios e perspectivas para as organizações. São Paulo: Senac, 2006. 396 p. 